\title{
EL MINISTERIO DE LA DIRECCIÓN ESPIRITUAL COMO EJERCICIO DE MISERICORDIA
}

DOI: https://doi.org/10.52039/seminarios.v62i216.151

RAMÓN GARCÍA REYNOSO*

\section{PREÁMBULO}

Agradezco la iniciativa de esta convocatoria y de cada esfuerzo para que nuestra querida Universidad Pontificia de México esté vez más presente en el corazón de los esfuerzos eclesiales que buscan la verdad ${ }^{1}$.

Presento mi reflexión en cinco momentos: introducción; marco teórico; la dirección espiritual en metáforas; mi experiencia de vivir la dirección espiritual como ministerio misericordioso; conclusión.

\section{INTRODUCCIÓN}

-¿Qué estás haciendo, padre?

-A tus órdenes -le respondí a mi hermano presbítero.

Esta respuesta provocó paz y salud espiritual a un sacerdote que buscaba ser escuchado. Inicio con esta experiencia. En efecto: «no hay una sola persona que no desee ser escuchada». Aquí radica el fundamento antropológico de la dirección espiritual. Pero este ministerio de misericordia hunde sus raíces más hondas en la experiencia teologal que permite la acción misteriosa de la Trinidad tanto en la persona acompañada como en la que acompaña. Experiencia teologal que se realiza no en un diálogo, sino en un «triálogo» ${ }^{2}$, donde Dios, el Padre Bueno se hace presente con sus entrañas misericordias, haciendo de las personas «testigos de primera mano» ${ }^{3}$ de la acción salvífica de nuestro Dios.

* Sacerdote de la diócesis de Torreón. Licenciado en Teología dogmática y en Teología espiritual y formación de vocaciones. Actualmente es director espiritual de la residencia de sacerdotes y seminaristas de la Universidad Pontificia de México, y profesor de Teología espiritual y Dirección espiritual en la misma Universidad.

1. Cf. Papa Francisco, Mensaje al Episcopado Mexicano en la Catedral Metropolitana de México, 13 de febrero de 2016.

2. Cf. T. Rodríguez Miranda, La Dirección espiritual. Pastoral del acompañante espiritual, Buenos Aires 2006, 35.

3. C. Rodríguez, "Evoking hope», en W. Miller (ed.), Integrating Spirituality into Treatment, Washington D.C. 1999, 228. 
Estoy convencido de que hoy estamos «en tiempos del Espíritu». Vivimos «tiempos intrépidos». Son tiempos que requieren creatividad, audacia, valentía. ¡Tiempos del Espíritu! El mismo Espíritu de la creación, el mismo que habló por los profetas, el que cubrió las entrañas de la joven María de Nazaret, el Espíritu que animó la vida y el ministerio de Jesús, es el mismo Espíritu que habita el mundo y la Iglesia.

El nuestro, es también tiempo del Espíritu. Me gusta describir la espiritualidad como «toda la vida animada por el Espíritu Santo». Hablar de dirección espiritual hoy nos lleva a una primera afirmación fundamental: «La espiritualidad cristiana tiene carta de ciudadanía en el mundo moderno" y por tanto, todas sus expresiones y una de ellas es la dirección espiritual.

En este panel quiero, compartir, desde la teología espiritual, pero sin quedarnos en meros conceptos, la experiencia de ser acompañado que el Señor me ha concedido recibir durante más de treinta años y la experiencia de acompañar, durante quince años, a laicos, laicas, seminaristas, religiosas, religiosos, monjes, monjas, diáconos y presbíteros. Las experiencias que compartiré recogen, principalmente, lo vivido en el acompañamiento a hermanos sacerdotes.

\section{¿Qué queremos decir cuando decimos «Dirección espiritual»?}

Pienso que hoy vuelve a considerarse, y con mayor fuerza, la necesidad de la dirección espiritual. Cayó en desuso debido a una falsa concepción de sus características. Sucedió un fenómeno interesante: después de la crisis del postconcilio, cuando hubo muchas deserciones tanto de la vida sacerdotal como religiosa, se cuestionó la validez de un acompañamiento. Simplemente se dejó de acompañar y hubo varias generaciones sin esta experiencia. Al no haber personas que acompañaran, no había acompañados que se ejercitaran para poder convertirse posteriormente en acompañantes. Dicho coloquialmente: «quien no ha sido acompañado, no sabrá acompañar».

Hoy se revalora la dirección espiritual de manera sólida, desde la teología espiritual en diálogo con las ciencias humanas. Asistimos a un florecimiento de la espiritualidad eclesial y el deseo de formar cristianos adultos. En efecto, la dirección espiritual hunde sus raíces en la experiencia humana. En ese sentido se convierte en una exigencia para quien quiere vivir hoy con autenticidad su fe cristiana, pues la dirección espiritual es la capacidad de «leer» en el secreto de los corazones de las personas. Por tanto, pertenece al hombre-creyente ${ }^{4}$.

En nuestra vivencia cristiana diaria, tenemos la convicción profunda de que Dios nos conoce, nos mira, nos escucha, nos atiende, está cerca de nosotros, nos espera tras nuestras caídas. Nos sabemos profundamente acompañados:

4. Sobre esto, cf. T. Rodríguez Miranda, La Dirección espiritual. Pastoral del acompañante espiritual, 301. 
para experimentarnos hijos; para ser hermanos, para orar con confianza, para ponernos en libertad delante de Dios y vivir de acuerdo a su voluntad ${ }^{5}$.

Porque este Dios con el que nos relacionamos está vivo y «en Él vivimos, nos movemos y existimos» (Hch 17, 28). Somos creados por Él y estamos llamados a retornar a Él a través de un camino espiritual que implica toda nuestra vida y nuestra persona. Por eso, todo camino espiritual abarca toda la existencia histórica. El acompañamiento espiritual pretende ayudarnos en ese camino de retorno al Padre misericordioso ${ }^{6}$.

Como ya dije, en la dirección espiritual se realiza un «triálogo» donde están presentes el Espíritu de Dios, el acompañante y el acompañado. «La relación es triangular, porque Dios inspira por igual a ambos interlocutores y porque el Espíritu está siempre presente en el proceso espiritual que se acompaña» ${ }^{7}$

Esta anotación es muy importante y marca un hito nuevo en la manera de comprender la dirección espiritual; pues de manera distinta a como se concibió en otras épocas de la historia, el director espiritual o acompañante no tiene la privatización del Espíritu, sino que también el acompañado posee el don de discernimiento. Se trata de que juntos lleguen a conocer la voluntad de Dios, donde el principal protagonista en esta tarea es el Espíritu Santo.

\section{¿Dirección espiritual? ¿Acompañamiento?}

Al recuperarse la necesidad de la dirección espiritual, vienen con este deseo de crecer en la fe, una serie de nombres que pudieran generar confusión. Lo primero que quiero recordar es que la dirección espiritual se distingue claramente tanto del sacramento de la reconciliación, como de la entrevista formativa y de la terapia psicológica ${ }^{8}$.

Existen variedad de nombres; desde los tradicionales: «dirección espiritual»; «maestro y discípulo»; «padre espiritual»; «padre e hijo»; «director-discípulo»; hasta los más actuales: «diálogo pastoral»; «coloquio espiritual»; «guía»; «encuentro de ayuda espiritual»; «relación de ayuda»; «entrevista pastoral»; «counseling religioso»; "coaching espiritual»?.

En lo personal, como hijo de mi tiempo, he experimentado cierta resistencia a seguirle llamando «dirección espiritual» y en ocasiones he preferido llamarle «acompañamiento espiritual». Sin embargo, he encontrado un argumento que me parece claro para seguir usando el nombre clásico: «Dirección espiritual» ${ }^{10}$.

5. Cf. L. M. García Domínguez, El libro del discípulo. El acompañamiento espiritual, Santander 2011, 15-16.

6. Ibid.,16.

7. Cf. R. Vieyra Braun, Sacramento de la Reconciliación, entrevista de formación y dirección espiritual»: Kyrios 2 (1996) 15-20.

8. Ibid., 15-20.

9. Cf. L. M. García Domínguez, El libro del discípulo, 16.

10. Cf. ibid., 16. 
El argumento es este: «Hemos querido expresamente mantener el término dirección espiritual pero rescatándolo, o 'resucitándolo' a su 'vida nueva'. Rescatándolo de la connotación de 'directivismo' y resucitándolo a la connotación de encontrar la dirección, el sentido, el derrotero, la orientación, el rumbo hacia el Padre, acompañado del servicio de un amigo desinteresado y experimentado. Entonces la palabra 'dirección' no significa aquí ni dirigir ni ser dirigido, sino más bien 'encontrar la dirección'»"11.

Considerando las nuevas perspectivas de la comprensión de la espiritualidad hoy, podemos decir que los cometidos decisivos de la dirección espiritual son cuatro ${ }^{12}$ : la guía hacia el propio conocimiento; la preparación para aceptarse a sí mismo; la ayuda para desprenderse del propio yo; y, principalmente, la búsqueda común de la voluntad concreta de Dios.

A continuación, voy a destacar varios derroteros por los que intuyo que el Espíritu Santo pretende llevarnos en el arte misericordioso de la dirección espiritual.

\section{ACOMPAÑAR POR MEDIO DE METÁFORAS ${ }^{13}$}

La metáfora es sugerente cuando se trata de hablar de los dinamismos del Espíritu. Permítanme sugerir tres metáforas para referirme a la dirección espiritual como ejercicio de misericordia.

Después de cada metáfora, propongo una convicción que quiere resaltar varias implicaciones de la dirección espiritual en el mundo contemporáneo y la certeza de que, por la entrañable misericordia de Dios, en cada encuentro, en cada entrevista, nos visita el Sol que nace de lo alto (cf. Lc 1, 78).

\section{Primera metáfora: Ordenar el caos interior}

La espiritualidad ha hecho de la ascesis un camino para buscar un cierto orden dentro del caos. La espiritualidad no niega que vivimos en un caos, pero a la vez siempre ha lanzado pistas que nos puedan acompañar para orientar y ordenar nuestra vida ${ }^{14}$. En la Biblia, el tema luz/tinieblas aparece de forma muy recurrente ${ }^{15}$.

11. T. Rodríguez Miranda, La Dirección espiritual. Pastoral del acompañante espiritual, 7.

12. Cf. F. Wulj, «Dirección espiritual», en http://www.mercab.org/Mundi/2/direccionespiritual.htm

13. Cf. X. Quinzá Lleó, Ordenar el caos interior. Una propuesta espiritual, Santander 2011.

14. Cf. X. Quinzá, Ordenar el caos interior. Una propuesta espiritual, Santander 2011. Es muy interesante el concepto que el autor tiene de la metáfora del caos: «Caos que es, al mismo tiempo, creación y destrucción, muerte y renacimiento constante. El flujo del caos sigue trabajando en nosotros; más aún, es el retrato de cada uno» (p. 13).

15. Cf. P. Girono, Luz/Tinieblas, en P. Rossano - G. Ravasi - A. Girlanda (eds.), Nuevo diccionario de teología bíblica,Madrid 2001, 1077-1084. 
Llama la atención el inicio de la Sagrada Escritura: «Al principio creó Dios el cielo y la tierra. La tierra era una soledad caótica y las tinieblas cubrían el abismo, mientras el espíritu de Dios aleteaba sobre las aguas. Y dijo Dios: 'Que exista la luz'. Y la luz existió. Vio Dios que la luz era buena y la separó de las tinieblas. A la luz la llamó día y a las tinieblas noche» (Gn 1, 1-3).

La Biblia de América, cuya traducción he leído, coloca cuatro realidades: soledad-caótica-tinieblas-abismo. La Biblia de Jerusalén habla de caos y confusión, y de la oscuridad que cubría el abismo. En hebreo, la pronunciación es tremendamente sonora tohû, bohû, tehom. Tohû (desierto) y bohû (vacío) es una bina que designa un completo desorden, una ausencia de vida y fecundidad. Tehom hace alusión al abismo. Estos tres términos hebreos presentan un cuadro negativo con el que contrastará la novedad de la intervención del Dios personal creando todo con su Palabra. Dios llama a la vida con su Palabra.

La luz es la primera bienaventuranza del Dios que crea: «Vio Dios que la luz era buena y la separó de las tinieblas» $(G n 1,4)$. Por eso, es la realidad que guía toda la obra creadora de Dios: el cielo, el mar, la tierra, las plantas, los astros, los peces, las aves, los animales, el hombre «nacen a la luz».

Convicción: La dirección espiritual es, para el hombre de hoy, luz que pone orden al caos interior. El acompañamiento ha de brindar la luz de la misericordia que nos recuerda que para Dios nuestro Padre no es oscura la tiniebla, pues para Él la noche brilla como el día (cf. Sal 139,12). No hay noche sacerdotal en la que Dios no pueda volver a decir su protopalabra: «Que exista la luz» ( $G n$ $1,4)$. Además, la dirección espiritual actualiza, de algún modo el encuentro de Nicodemo con Jesús (cf. Jn 3, 1-21): el «fariseo y personaje importante» buscó a Jesús de noche y el texto juánico da testimonio de que el encuentro acaba en la luz: «Aquel que actúa conforme a la verdad, se acerca a la luz, para que vea que toda su conducta está inspirada por Dios» $(\mathrm{Jn} 3,21)$

\section{Segunda metáfora: Pulir el corazón}

La dirección espiritual quiere ayudar a formarnos bajo la acción del Espíritu. Cuando Dios actúa por su gracia, salvando, renovando nuestro corazón, lo hace como Creador. Nos re-crea y esta acción se realiza en nuestra existencia humana histórica, contingente.

Jesús involucra toda su humanidad en la formación de los suyos. Jesús, el Hijo amado del Padre (cf. Mc 1, 11) manifiesta este amor poniéndose a favor de los demás, especialmente de los que sufren. En todas las culturas, el amor es expresado con términos de interioridad; hoy, al hablar del amor, el corazón es un signo universal; corazón es una "palabra-símbolo».

En el hebreo bíblico, leb es una palabra que puede traducirse como corazón, entraña, intimidad, modo de ser. Dios ha mostrado su entraña amorosa en su Hijo hecho hombre; en efecto, Jesús es la revelación de la ternura y misericor- 
dia del Padre. Jesús es la entraña amorosa del Padre ${ }^{16}$; en la carne de Jesús, tocamos la vida del Padre ${ }^{17}$.

Teológicamente atrae el significado etimológico de donde se deriva la palabra misericordia: rahamim (en hebreo) significa entrañas, útero, dar vida, alimentar, cuidar. Entonces Yahvé rahamim significa que Dios Padre nos lleva en sus entrañas maternas. El verbo griego splanjnizomai significa literalmente que a Jesús le tiemblan las entrañas al ver a la gente sufriendo ${ }^{18}$.

Los discípulos de Jesús estamos llamados a convertirnos en hombres con entrañas de misericordia; por eso Jesús, percibiendo a la multitud hambrienta les ordena: «Denles ustedes de comer» (Mc 6, 37).

Convicción: La dirección espiritual ha de suscitar hoy, personas con entrañas de misericordia, capaces acompañar a sus hermanos.

Una consigna podría ser: acompañar y dejarnos acompañar hasta que se formen en nosotros las entrañas de misericordia al estilo de Jesús. La dirección espiritual toca el corazón traspasado del sacerdote para ayudarlo a configurarse con el de Jesús Buen Pastor Misericordioso.

\section{Tercera metáfora: El «de dos en dos» evangélico}

Ni la llamada ni la misión son exclusivas, tampoco son una apropiación individualista; Jesús llama a quien quiere, y el enviado realiza la obra en su nombre. La perspectiva del apoyo entre mediaciones se percibe muy clara en el evangelio de Marcos. El Evangelista conserva el nombre de los Doce. En el texto, vemos cómo Jesús siempre llama en comunidad y llama para hacer comunidad. Jesús Ilama a sus primeros discípulos de dos en dos (cf. 1, 16-19); después los envía de la misma manera (cf. 6, 6b-13); son dos de los suyos a los que envía a preparar la cena Pascual (cf. 14, 13); en momentos importantes Jesús se hace acompañar de tres apóstoles: Pedro, Santiago y Juan (cf. 5, 37; 9, 2); y en una ocasión también se integra Andrés (cf. 1, 29).

Resulta significativo que siempre que uno de los apóstoles se encuentra solo, su misión fracasa: Pedro aseguraba que no negaría a Jesús como los demás (cf. 14, 29.31) y termina negándolo (cf. 14, 30.66-72); Judas Iscariote lo traiciona (cf. 3, 19; 14, 10-11.17-20).

Convicción: En la dirección espiritual es fundamental la alteridad. Nos situamos en la perspectiva del otro, pero como signo de la referencia a Dios, fuente

16. Cf. Papa Francisco, Misericordiae vultus, 1.

17. Cf. Id., Homilía en la Santa Misa con Consagrados, Sacerdotes y Seminaristas en Morelia, 16 de febrero de 2016.

18. A Jesús se le estremece el corazón ante el dolor humano porque es el amor entrañable de Dios. Jesús acompaña, toca y se compadece del leproso (cf. Mc 1, 41), de las multitudes que andan como ovejas sin pastor y que están hambrientas (cf. Mc 6, 34; 8, 2), del endemoniado de Gerasa (cf. Mc 5, 19) y del epiléptico (cf. Mc 9, 22). Jesús da testimonio y muestra el rostro del Padre misericordioso al compadecerse de los débiles. 
de la vida. Es decir, la comunicación con el otro, por el mismo hecho de ser otro, nos abre a las señales que Dios nos quiere dar para compartirnos sus dones. Mediante la dirección espiritual, acompañante y acompañado aprenden a abrirse a Dios que es alteridad y donación.

La dirección espiritual nos recuerda que necesitamos amigos en Dios. La persona sola, termina por suicidarse; es decir, sin la ayuda en el crecimiento de la fe, no se vive con plenitud. ¡Ay del solo! (cf. Ecl 4, 10). La dirección espiritual nos recuerda la experiencia fundante del discipulado: «ser llamado y enviado de dos en dos, ser llamados y enviados en comunidad». La apertura a la alteridad es una de las grandes tareas de nuestro tiempo a la que nos está urgiendo la nueva concepción de la dirección espiritual. Somos urgidos a vivir una misericordiosa alteridad. Vivir desde la relación del abrazo trinitario ${ }^{19}$.

«DANOS ENTRAÑAS DE MISERICORDIA ANTE TODA MISERIA HUMANA» (Plegaria eucarística $\mathrm{Vb}$ )

\section{Experiencias de misericordia en la Dirección Espiritual}

Comento ahora, como una oportunidad de recoger experiencialmente las horas de acompañamiento que he vivido; cómo he sido testigo de la misericordia de Dios. Brevemente comparto la vida, vida tocada por el Espíritu, vida transformada, vida enriquecida desde la vida de mis hermanos sacerdotes que he podido acompañar y cuya experiencia es también alimento de mi vocación.

\section{Luz-corazón-comunidad}

Estas metáforas me han acompañado en el ejercicio del ministerio de la dirección espiritual. Jesús compartió a sus discípulos una dimensión de su identidad: «Yo soy la luz del mundo» (Jn 8, 12); «Ustedes son la luz del mundo» (Mt 5, 14).

Cada encuentro vivido en la dirección espiritual es crear el espacio para redimensionar esta característica. Muchos sacerdotes han descuidado el acompañar y dejarse acompañar. La vida ministerial absorbe, la caridad pastoral a veces nos hace olvidarnos de nosotros mismos. Sin embargo, es necesario parar. Parar para ordenar la vid, para ordenar el caos, para preguntarnos: «La manera en que estoy viviendo ¿es la manera que Dios quiere que viva?».

Una pregunta que sacude pero que está en cada corazón sacerdotal. Hermanos sacerdotes, no tengamos miedo a abrir nuestras entrañas ante el hermano: nos necesitamos para ayudarnos a ser mistagogos que nos ayudemos a entrar en las entrañas del Padre Bueno. Nada más triste que escuchar de un

19. Cf. L. M. Ayala Díaz, La entrevista de dirección espiritual desde el abrazo trinitario»: Kyrios 18 (2005) 25-40. 
sacerdote, como me tocó escucharlo hace varios años: "Ya no confío en ninguno de estos de mi presbiterio». El corazón traspasado de un sacerdote cabe en la miseria del otro. No podemos avanzar solos. La fraternidad sacerdotal es una realidad querida por Jesús, el hombre de la comunión.

La dirección espiritual es una vereda evangélica que hay que recorrer «de dos en dos», pero involucrando al Resucitado que camina a nuestro lado: en «triálogo», pues como ya hemos insistido. No necesitamos tomar nada para el camino, ni pan, ni morral, ni dinero, ni dos túnicas; nada, nada: ¡llevamos a nuestro hermano! (cf. Mc 6, 7ss), sacramento del Hijo del Hombre. Hagamos caminos evangélicos. Acompañarnos es ser misericordiosos entre nosotros y convertirnos en testigos para la comunidad humana y eclesial.

\section{Sacerdotes re-creados}

He escuchado de muchos sacerdotes expresiones pascuales como las siguientes: «quiero renovar mi ministerio»; «me quiero preparar la celebración de mi aniversario»; «deseo hablar de mi historia»; «anhelo reconciliarme conmigo mismo»; "quiero iniciar un camino de acompañamiento». Con sorpresa y a la vez con esperanza de re-comenzar hay quien dice: «en el seminario no le di importancia a la dirección espiritual, por falta de atención del equipo formador y principalmente por mi negligencia». Son expresiones pascuales, porque un sacerdote que desea volver a la fuente y consolidar su vocación, es un sacerdote que resucita, que deja que su existencia sea pascualizada, porque es re-creada por el Dios de la vida.

Cuántos hermanos sacerdotes he visto volver a amarse, a perdonarse, a re-descubrir su pasión por el servicio. La dirección espiritual ha sido para algunos el espacio sagrado que les permitió no abandonar el ministerio. Sí, la dirección espiritual tiene una hermosa dimensión pascual; es espacio que resucita vidas sacerdotales, que anima, re-crea, re-hace ministerios, porque el sacerdote se deja tocar, en cada entrevista, por el Caminante Resucitado que vuelve a encender el corazón con su presencia resucitada y resucitadora (cf. Lc 24, 32).

\section{Lágrimas sacerdotales}

Las lágrimas son expresión de la hondura de la vida. Las lágrimas son una expresión evangélica: Jesús llora por su hermano y amigo Lázaro. Pedro llora su pecado. Las mujeres Iloran al ver al Profeta Galileo que no tiene aspecto de hombre. El sacerdote, sí, el sacerdote, hombre de Evangelio, también llora. En su visita a Manila en 2015, el papa Francisco recordaba que a todas las personas nos hace falta llorar para aproximarnos a la ternura de Dios, para expresarnos y vivirnos como auténticos humanos, porque algunas realidades de la vida se ven solamente con los ojos limpios por las lágrimas. Así lo recordó en Ciudad 
Juárez: «Capaces de llorar. Llorar por la injusticia, llorar por la degradación, llorar por la opresión. Son las lágrimas las que pueden darle paso a la transformación, son las lágrimas las que pueden ablandar el corazón, son las lágrimas las que pueden purificar la mirada y ayudar a ver el círculo de pecado en el que muchas veces se está sumergido. Son las lágrimas las que logran sensibilizar la mirada y la actitud endurecida y especialmente adormecida ante el sufrimiento ajeno. Son las lágrimas las que pueden generar una ruptura capaz de abrirnos a la conversión $»^{20}$.

La dirección espiritual ha sido para mí un espacio para contemplar las lágrimas de mis hermanos. Lágrimas que reconocen la sublimidad del don del sacerdocio en la pequeñez de la humanidad; lágrimas que expresan el error, el pecado, la tibieza; lágrimas que recuerdan la historia de infidelidad, pero también lágrimas que son despojo de sí mismo para volver a ser totalmente de Dios. Es conmovedor experimentar en este "gesto humanotototote» (como me gusta llamarlo), el deseo ardiente de reencontrarse con la fuente de la vida, con el Dios de la eterna misericordia.

La dirección espiritual recoge esta experiencia profundamente vivencial, porque también hemos llorado de alegría por el don de la vida nueva, por el gozo de intuir esperanza y por reconocer nuevos senderos por donde quiere conducirnos el incasable Espíritu del Señor.

\section{Conversión sacerdotal}

La vocación y la conversión son llamadas. Dios siempre toma la iniciativa: «Conviértenos Señor y nos convertiremos» (Lam 5, 21). La dirección espiritual es el «triálogo» donde se acoge la esperanza que suscita el Espíritu para una vida nueva.

Cada sacerdote que se acerca a la dirección espiritual recibe una llamada, eco de la llamada inicial, memorial de la vocación primera: hijos del Padre Bue$\mathrm{no}^{21}$. El mismo hecho de programar entrevistas, sugerir caminos, confrontar la existencia, es un indicio, desde que el sacerdote toca a la puerta del director espiritual, de que quiere vivir la conversión. Vivir ese shub bíblico que mencionado más de mil veces invita a cambiar de dirección; vivir esa matánoia griega que provoca conversión en la manera de pensar-sentir-hacer. La dirección espiritual es una renovación de la vocación. Es Dios quien acompaña y cambia nuestras rutas; Él transforma mente-corazón-manos para pensar-sentir-obrar de acuerdo a su misericordia. ¡Dirección espiritual: bendito espacio de conversión!

20. Papa Francisco, Homilía en la Santa Misa celebrada en Ciudad Juárez, miércoles 17 de febrero de 2016.

21. Cf. Papa Francisco, Homilía en la Santa Misa celebrada en Morelia, martes 16 de febrero de 2016. 


\section{Humanización del sacerdocio}

El sacerdote es un hombre, «nada del sacerdote nos es ajeno». La dirección espiritual es espacio para encontrar el paso de Dios por la historia, por el gozo y la tristeza, por la alegría y el sufrimiento con los que son tejidas las historias humanas. El misterio de la encarnación del Hijo de Dios permea cada entrevista de acompañamiento: Él se ha encarnado y «entierrado» entre nosotros.

¡Qué dicha poder escuchar la narración de la historia sacerdotal en las entrevistas de dirección espiritual, ahí donde Dios nos vivifica!. Delante del acompañante está un ser humano de carne y hueso, no un sacerdote-super héroe. La dirección espiritual me ha venido haciendo más humano, gozoso de la vida humana y sereno ante nuestra vulnerabilidad, siempre abrazada por la paz que sólo el Señor puede dar.

\section{Sacerdote: Icono de la Trinidad}

El Misterio Trinitario es fuente y culmen de toda Teología Espiritual. Por tanto es también fuente y culmen de la dirección espiritual. Nos acompaña el Padre que nos conoce y ama desde la eternidad, que con entrañas de misericordia nos ha creado con la ternura de su amor; nos acompaña su Rostro Misericordioso, Jesús de Nazaret que ha restaurado la creación entera; nos acompaña Ruah Yahvé, aliento de Vida, fuego, Espíritu Santo que como compañero de camino lleva a plenitud la historia de Dios en el hombre. El Misterio Trinitario nos acompaña: el Padre Creador; el Hijo Re-creador; el Espíritu Santo Trans-creador ${ }^{22}$.

Cada encuentro en dirección espiritual es una experiencia teologal donde se descubre cómo «la Trinidad se pasea», mientras el acompañante y el acompañado hablan y se escuchan. Es un momento privilegiado para redescubrir nuestra vocación, pues en efecto, según el evangelio de Marcos, en el diálogo intratrinitario fue creada la comunidad de los Doce (cf. Mc 3, 13-19). Así se expresa en el original griego: kai epoiesen dodeka («y creó a Doce»; Mc 3, 14).

Por eso, la dirección espiritual recuerda al sacerdote que al ser llamado, ha sido creado. En esta llamada está la raíz teologal de su ministerio: ser-hombrede-la-Trinidad ${ }^{23}$. De ahí que la dirección espiritual entre sacerdotes nos impulse a ser portadores de la misericordia del Padre (patrófanos); a ser anunciadores de Jesús, misericordia encarnada (cristóforos); y nos concede la gracia de vivir con corazón misericordioso por la acogida y el ofrecimiento del don del Espíritu (pneumatódoros) ${ }^{24}$.

22. Cf. Ph. Rosato, Introducción a la Teología de los Sacramentos, Estella 1994.

23. Cf. Juan Pablo II, Mensaje a Sacerdotes en la Catedral de Vilnius, Lituania, 4 de septiembre de 1993.

24. Cf. A. Triacca, Reflexión teológico-Trinitaria sobre el Ministerio Sacerdotal, en N. Silanes, Ministerio Sacerdotal y Trinidad. XXII Semana de estudios Trinitarios, Salamanca 1998, 149-182. 
¡Qué gozo que, como sacerdotes, nos experimentemos creados, re-creados y trans-creados gracias a la dinámica trinitaria que abraza la dirección espiritual! ${ }^{25}$

\section{Sacerdote: obra de misericordia}

En su reciente mensaje de cuaresma, el papa Francisco, menciona nueve verbos que llaman profundamente la atención, porque es una manera contundente y directa de acercarse al Evangelio. La dirección espiritual ayuda a retomar estos verbos para poner delante del sacerdote a los vulnerables por quienes se ha consagrado para: nutrirlos-visitarlos-consolarlos-educarlos-aconsejarlos-enseñarlos-perdonarlos-amonestarlos-rezar por ellos ${ }^{26}$.

En la dirección espiritual se toca la entraña del sacerdote, para que a su vez cada sacerdote toque la carne de Cristo en los hermanos y hermanas. Cuando se trata de «tocar», la dirección espiritual actualiza el evangelio, pues este verbo en griego, hapto, no es sólo un tocar físico, sino un tocar salvífico.

Cuando Jesús toca a alguien, no lo deja igual: lo transforma, lo libera, lo hace nuevo y establece una alianza con la persona. La dirección espiritual es pues una experiencia «háptica»: la Trinidad «toca» haciendo del acompañante y acompañado, unas personas nuevas, dispuestas a tocar con ternura y misericordia a cada persona y así transformarla.

El sacerdote, obra de Dios, creación de Dios, puede redescubrir, en la dirección espiritual, su llamado a ser entrañablemente misericordioso, como el Padre.

\section{Ministerio misericordioso en el Papa de la Misericordia}

No quiero perder la oportunidad de redactar algunos párrafos, haciendo una breve alusión a la reciente visita del papa Francisco a nuestro país, resaltando algunas expresiones, que sin hablar directamente de la dirección espiritual, nos ayudan a redimensionar el ministerio misericordioso de la escucha.

Oración y vida; vida y oración, bien pueden sintetizar la experiencia de dirección espiritual. Cada entrevista la comienzo con una oración y termino con la pregunta ¿qué te ha regalado Dios? La oración que prepara remota o inmediatamente el encuentro permite disponernos a la acción del misterio trinitario, nos abre a su don: Él mismo. En la dirección espiritual Dios no regala cosas, jÉl se nos da! La dirección espiritual es, por tanto, un espacio donde la vida se hace consciente porque se ora; y es un espacio donde se ora para luego contagiar vida cristiana plena. 25-40.

25. Cf. L. M. Ayala Díaz, «La entrevista de dirección espiritual desde el abrazo trinitario»,

26. Cf. Francisco, Mensaje para la Cuaresma de 2016. 
Es necesario tender manos, necesitamos de amigos que nos ayuden, que nos abracen; esto comienza con la «escuchoterapia». Estamos invitados a no esconder nuestras manos. El Señor nos manda oídos amigos, manos amigas para recuperar el encanto del encuentro; y la dirección espiritual es encuentro que nos permite descubrir a Dios que enciende en nuestro interior lo mejor de nosotros mismos para siempre volver a empezar.

La dirección espiritual es mano extendida de Jesús, que a través de la mediación del acompañante, nos ayuda a vivir a fondo, a descubrir que valemos la pena, nos recuerda nuestra identidad de ser fermento, sal y luz.

Cada entrevista en dirección espiritual puede ser una oportunidad para superar la acedía de la resignación; un espacio para hacer memoria creyente de lo que Dios ha hecho por su pueblo, con lo que Dios va haciendo en nuestra propia historia. En definitiva, la dirección espiritual es imagen del hijo que reencuentra su identidad re-aprendiendo a balbucear: Padre-Papá-Abba-Padre Nuestro.

\section{CONCLUSIÓN}

Hoy se hace indispensable la dirección espiritual; es necesario formarse en la cultura del acompañamiento. Urge preparar más agentes de pastoral comprometidos con este ministerio de misericordia que consiste en "entrar y tocar tierra sagrada» animados por el Espíritu.

Urge acompañar y dejarse acompañar. Acompañar los gozos y las esperanzas, las tristezas y las angustias de los hombres de nuestro tiempo, sobre todo de los pobres y de cuantos sufren (cf. GS 1); acompañar con pies descalzos y con creatividad espiritual.

Acompañar en tiempos difíciles: acompañar el sinsentido; la depresión; la sexualidad mal vivida; la inconsistencia; la muerte provocada por la violencia, el narcotráfico y la trata de personas; pero también acompañar la riqueza personal de cada ser humano, su esperanza, su dignidad. Acompañar y ser acompañados, para descubrir y vivir la voluntad del Dios de la misericordia en cada instante de nuestras vidas.

Es mi deseo de que cada vez haya más y mejores acompañantes: laicos, laicas, religiosos, religiosas y sacerdotes. Que cada vez seamos más los que nos dejemos acompañar para buscar la voluntad de Dios y entrar, juntos, con pies descalzos, al misterio de su misericordia. 